\title{
Penerapan GMP dan SSOP dalam Proses Produksi Rendang Daging di Produsen Rendang Istana Rendang Jambak
}

\author{
Application of GMP and SSOP in Production Process of Beef Rendang in Industry Istana Rendang Jambak \\ V. Indriani, A. Apriantini*, \& T. Suryati \\ Departemen Ilmu Produksi dan Teknologi Peternakan, Fakultas Peternakan, Institut Pertanian Bogor, \\ Jl. Agatis, Kampus IPB Darmaga, 16680 Bogor \\ *Corresponding author: astariapriantini@yahoo.com \\ (Received 30-06-2021; Revised 23-08-2021; Accepted 13-09-2021)
}

\begin{abstract}
Rendang is a Minangkabau typical food made from meat cooked with coconut milk and additional spices for 4-6 hours using a wood stove and a semi-closed place, where the rendang is made potentially contaminated with contamination during production. This study aims to evaluate the application of the basic requirements of food safety standards, namely GMP and SSOP during the production process at the rendang producer, Istana Rendang Jambak. Data were taken based on observations and interviews of workers and owners. The assessment of conformity with the application of GMP in rendang producers, Istana Rendang Jambak, obtained a score of $34.17 \%-85.00 \%$, with a deviation value of 213 from the overall value of 468 . The assessment of conformity with the application of SSOP obtained a value of $0.00 \%-68.75 \%$, with a deviation value of 79 from the overall value of 120 . Rendang Palace Jambak is sufficient to meet the principles of GMP, but does not meet FDA requirements regarding SSOP.
\end{abstract}

Keywords: GMP, rendang, SSOP

\begin{abstract}
ABSTRAK
Rendang adalah kuliner khas Minangkabau yang dibuat dari daging yang dimasak dengan santan dan tambahan bumbu selama 4-6 jam menggunakan tungku kayu dan tempat yang semi tertutup, tempat pembuatan rendang tersebut berpotensi untuk tercemar kontaminasi selama produksi. Penelitian ini bertujuan untuk mengevaluasi penerapan syarat dasar standar keamanan pangan yaitu GMP dan SSOP selama proses produksi di produsen rendang Istana Rendang Jambak. Data diambil berdasarkan observasi dan wawancara pekerja dan pemilik. Penilaian kesesuaian penerapan GMP di produsen rendang Istana Rendang Jambak memperoleh nilai 34.17\%-85.00\%, dengan nilai penyimpangan 213 dari nilai keseluruhan 468. Penilaian kesesuaian penerapan SSOP memperoleh nilai 0.00\%-68.75\%, dengan nilai penyimpangan 79 dari nilai keseluruhan 120. Istana Rendang Jambak cukup memenuhi prinsip-prinsip GMP, namun kurang memenuhi ketentuan FDA mengenai SSOP.
\end{abstract}

Kata kunci: GMP, rendang, SSOP

\section{PENDAHULUAN}

Produksi pangan di Indonesia terus mengalami perkembangan seiring dengan berkembangnya teknologi dan ilmu pengetahuan. Meningkatnya kesadaran terhadap pentingnya menjaga kesehatan menjadi alasan masyarakat mengkonsumsi makanan bergizi namun memiliki rasa yang nikmat. Hal tersebut juga berdampak terhadap meningkatnya konsumsi produk hasil ternak pada masyarakat. Produk hasil ternak saat ini menjadi salah satu pangan yang sangat penting. Kandungan gizi serta manfaat yang besar menjadikan produk hasil ternak seperti daging sapi, susu, telur, dan berbagai produk lainnya selalu menjadi pilihan utama.

Daging sapi di Indonesia umumnya diolah menjadi sate, bakso, dan sosis. Permasalahan yang umum dihadapi adalah daging sapi mudah mengalami pembusukan atau kerusakan (perishable food) yang disebabkan oleh cemaran fisik, biologi, dan kimia. Pengolahan daging sapi merupakan salah satu cara memperpanjang umur simpan daging. Salah 
satu produk olahan daging sapi adalah rendang. Rendang adalah makanan khas Minangkabau, Sumatera barat yang dibuat dengan bahan dasar daging, santan dan berbagai macam rempah, lalu dimasak dengan waktu yang cukup lama sampai menjadi kering dan berwarna gelap kehitaman, sehingga dapat disimpan dalam waktu lama. Namun, rendang termasuk salah satu makanan yang berpotensi tercemar secara kimia, biologis, dan fisik (Wicaksani dan Adriyani 2017). Sumber kontaminasi yang potensial pada daging rendang, yaitu: saat proses penyiapan bahan, pemasakan, serta proses setelah pemasakan terutama saat penyimpanan dan pengemasan. Kontaminasi selama proses pengolahan bisa disebabkan oleh lingkungan yang tidak bersih ataupun disebabkan oleh pekerja. Sumber kontaminasi lainnya yaitu kondisi tempat produksi rendang. Masyarakat Minangkabau biasa membuat rendang menggunakan tungku kayu bakar, dengan kondisi tempat pembuatan yang umumnya terbuka yang berpotensi terpapar kontaminasi.

Keamanan pangan berdasarkan Peraturan Pemerintah Republik Indonesia Nomor 28 Tahun 2004 tentang keamanan, mutu, dan gizi pangan adalah kondisi dan upaya yang dilaksanakan untuk mencegah pangan tercemar secara biologis, kimia, dan benda lainnya yang akan merusikan, menganggu, dan membahayakan kesehatan manusia. Penerapan good manufacturing practices (GMP) dan Sanitation Standard Operating Procedure (SSOP) diperlukan untuk mencegah terjadinya kontaminasi pangan yang dapat menyebabkan keracunan makanan atau foodborne disease. GMP merupakan tata cara melakukan produksi yang baik, prosedur pelaksanaan, pengendalian, dan pengawasan pelaksanaan proses produksi (Hanidah et al. 2018). Selain memperhatikan bahan baku dan proses, pengendalian sarana produksi yang baik, penting juga untuk menerapkan SSOP yang berfokus untuk menjaga higienitas dari mulai proses produksi hingga produk dipasarkan.

Istana Rendang Jambak merupakan salah satu produsen rendang yang berada di Mungka, Kabupaten Limapuluh Kota, Sumatera Barat. Produsen rendang Istana Rendang Jambak adalah produsen kecil dengan pekerja sebanyak 10 orang, penggunaan daging sapi setiap bulannya mencapai $300 \mathrm{~kg}$ dan penjualan hingga daerah Jabodetabek. Rasanya yang nikmat dan kepercayaan masyarakat yang tinggi terhadap produk Istana Rendang Jambak membuat produk ini terjual hingga ke Jepang. Oleh karena itu, penelitian mengenai pelaksanaan GMP dan SSOP pada proses produksi perlu dilakukan untuk menjamin keamanan dan kualitas produk yang dihasilkan.

Tujuan penelitian ini adalah mengevaluasi penerapan standar keamanan pangan yaitu GMP dan SSOP pada waktu persiapan bahan, proses pembuatan rendang daging, penyimpanan rendang daging dan pengemasan. Evaluasi dilakukan untuk memeriksa tingkat penerapan GMP dan selama proses produksi Istana Rendang Jambak, Kecamatan Mungka Kabupaten Limapuluh Kota.

\section{MATERI DAN METODE}

Penelitian ini dilaksanakan di tempat produksi rendang Istana Rendang Jambak yang berada di Kecamatan
Mungka, Kabupaten Limapuluh Kota, Sumatera Barat. Pengumpulan data dilakukan dengan mendatangi tempat produksi rendang, mulai dari persiapan, pengolahan dan pengemasan, data dikumpulkan melalui observasi, wawancara, dan kuisioner, lalu dilakukan penilaian dan dokumentasi. Wawancara dan kuisioner dilakukan kepada pemilik usaha dan karyawan. Selama pengambilan data dan observasi dilakukan dokumentasi berupa foto, untuk menjadi bukti.

Penerapan GMP yang diperiksa berdasarkan dengan paraturan Keputusan Menteri Kesehatan No.23/ MEN.KES/SK/I/1978 tentang cara produksi makanan yang baik. Penerapan SSOP yang diperiksa berdasarkan penelitian Triharjono et al. (2013). Data yang didapat kemudian dibandingkan dengan kondisi lapang dan kondisi seharusnya, dan dianalisis secara deskriptif menggunakan tabel dan dijelaskan dalam bentuk naratif. Menurut Lukman (2001) rumus yang digunakan untuk memperoleh nilai kesesuaian penerapan GMP dan SSOP dengan jumlah aspek yang sesuai dengan poin kesesuaian yang ditentukan yaitu:

$$
Y=(n 0 \times 0)+(n 1 \times 1)+(n 2 \times 2)+(n 3 \times 3)+(n 4 \times 4)
$$

\section{Keterangan:}

$\mathrm{Y}=$ nilai total penerapan yang didapatkan

n $0=$ jumlah aspek dengan nilai 0 dalam table penilaian n $1=$ jumlah aspek dengan nilai 1 dalam tabel penilaian n $2=$ jumlah aspek dengan nilai 2 dalam tabel penilaian n 3 = jumlah aspek dengan nilai 3 dalam tabel penilaian n $4=$ jumlah aspek dengan nilai 4 dalam tabel penilaian

Penilaian:

0 = penyimpangan yang terjadi $0 \%$ (penerapan memenuhi)

1 = penyimpangan yang terjadi $1-25 \%$ (penerapan cukup memenuhi)

2 = penyimpangan yang terjadi $26-50 \%$ (penerapan kurang memenuhi)

3 = penyimpangan yang terjadi $51-75 \%$ (penerapan sangat kurang memenuhi)

4 = penyimpangan yang terjadi $>75 \%$ (penerapan tidak memenuhi)

Nilai total penerapan yang didapat (Y) kemudian disesuaikan dengan skala persentase yang telah ditentukan berdasarkan nilai penuh pada poin untuk mendapatkan klasifikasi aplikasi di tempat produksi yaitu:

80-100\% = nilai kesesuaian aspek penerapan GMP memenuhi

60-79\% = nilai kesesuaian aspek penerapan GMP cukup memenuhi

$40-59 \%=$ nilai kesesuaian aspek penerapan GMP kurang memenuhi

20-39\% = nilai kesesuaian aspek penerapan GMP sangat kurang memenuhi

$0-19 \%=$ nilai kesesuaian aspek penerapan GMP tidak memenuhi 


\section{HASIL DAN PEMBAHASAN}

\section{Proses Produksi Rendang Daging}

Proses produksi merupakan suatu kegiatan yang terdiri dari beberapa faktor untuk menciptakan suatu produk yang bermanfaat bagi konsumen. Proses produksi di Istana Rendang Jambak terdiri atas penerimaan bahan baku, pengolahan rendang, pengemasan rendang, dan penyimpanan rendang. Proses produksi yang baik dan benar dapat menjaga keutuhan produk hingga ke tangan konsumen.

\section{Penerapan Good Manifacturing Practices (GMP)}

Rumah produksi rendang Istana Rendang Jambak belum menerapkan GMP dengan baik. Penilaian penerapan GMP ini mengacu pada Keputusan Menteri Kesehatan No.23/MEN.KES/SK/I/1978 tentang cara produksi makanan yang baik. Aplikasi GMP di lapangan beserta kondisi seharusnya pada produsen Istana Rendang Jambak dapat dilihat pada Tabel 1.

\section{Lokasi dan Lingkungan}

Lokasi dan lingkungan tempat proses produksi Istana Rendang memiliki nilai cukup memenuhi yaitu dengan nilai penerapan GMP $67.86 \%$. Lingkungan sekitar bangunan produksi cukup jauh dari kawasan perumahan, tertata rapi serta tidak bersemak, tidak berada pada daerah mudah banjir dan tidak ada genangan air. Namun disekitar tempat produksi terdapat kolam ikan, jalan menuju tempat produksi sempit dan sulit dilalui. Lokasi produsen merupakan faktor penting yang harus diperhatikan karena berpengaruh terhadap lalu lintas dan keluar masuk bahan dalam proses produksi dan kegiatan lainnya, sedangkan lingkungan di sekitar bangunan produksi terawatt dengan baik, harus bersih dan terbebas dari sumber pencemaran (Rudiyanto 2016).

\section{Bangunan}

Bangunan unit produksi harus memiliki ruangan pokok dan ruangan pelengkap. Ruangan pokok terdiri atas ruangan penerimaan barang, ruangan produksi, dan ruangan penyimpanan, sedangkan ruangan pelengkapan terdiri atas toilet, ruang istirahat, dan ruang makan. Secara keseluruhan penilaian terhadap bangunan produksi adalah 34.17\% dan dikategorikan sangat kurang memenuhi. Bangunan produksi terdiri atas ruangan produksi (ruang pokok) yang dibagi menjadi ruang persiapan bahan dan ruang pemasakan rendang, ruang penyimpanan hasil produksi, ruangan pengemasan dan ruang penyimpanan peralatan (ruang pelengkap). Susunan ruangan sudah sesuai dengan proses produksi ruang penyimpanan bahan mentah, ruang pemasakan dan ruang penyimpanan produk jadi berada terpisah dan tersusun sesuai urutan, namun antara ruang penerimaan barang dan ruang produksi dibatasi dengan kain yang kurang efektif untuk membatasi antar ruangan, sehingga memungkinkan terjadinya kontaminasi silang.

Lantai pada ruangan persiapan dan pemasakan terbuat dari semen, terdapat banyak retakan pada lantai, pertemuan dinding dan lantai membentuk sudut siku-siku sehingga ruangan tersebut akan sangat sulit untuk dibersihkan dan akan terjadi akumulasi kotoran yang dapat menyebabkan cemaran. Berbeda dengan ruangan penyimpanan yang lantainya terbuat dari keramik tidak ada retakan, namun pertemuan antara lantai dan dinding tetap membentuk sudut siku-siku. Kontruksi atap terbuat dari seng yang tahan terhadap cuaca, ringan, tidak mudah mengelupas serta tempat produksi tidak memiliki langit-langit.

Dinding pada ruang penyimpanan bahan mentah dan pengolahan tidak memenuhi persyaratan GMP, dinding ruangan pengolahan terbuat dari tembok setinggi $1.5 \mathrm{~m}$ yang berarti hanya menutupi setengah bangunan. Hal ini disebabkan karena proses pembuatan rendang yang menggunakan tungku kayu bakar dan menyebabkan ruangan menjadi sangat panas jika tertutup tembok hingga bagian atas bangunan. Dinding tempat produksi memiliki warna gelap yang disebabkan oleh asap dari kayu bakar, bertekstur halus, kuat dan tahan lama, serta tidak mudah mengelupas. Tempat pengolahan dan penyimpanan bahan tidak memiliki jendela dan ventilasi, ruangan pengolahan hanya ditutupi dengan kawat untuk mencegah hewan besar masuk. Namun ruang pengemasan dan penyimpanan memiliki jendela dengan jarak $1 \mathrm{~m}$ dari lantai. Ruang pengolahan tidak menggunakan jendela agar udara bisa masuk dan tidak panas.

Pintu keluar terbuat dari bahan kayu dan tripleks, tahan lama, tidak mudah rusak, dan dalam kondisi yang baik. Pintu membuka ke arah dalam yang dapat menyebabkan ruangan menjadi lebih sempit dan mengurangi penggunaan ruangan secara optimal. Penerangan tempat pengolahan saat siang hari berasal dari cahaya matahari dan lampu digunakan saat gelap ataupun cuaca buruk, dan lampu yang ada ditutupi dengan menggunakan plastik. Kondisi lampu yang digunakan tidak semuanya memberi penerangan yang cukup, lampu pada ruangan penyimpanan remang-remang sedangkan lampu ditempat pengolahan cukup terang.

\section{Fasilitas Sanitasi}

Sanitasi merupakan faktor yang harus diperhatikan terutama ketersediaan air bersih, pembuangan sampah, pengolahan air limbah, dan pencemaran tanah (Kasnodihardjo dan Elsi 2013). Fasilitas sanitasi secara keseluruhan kurang memenuhi dengan nilai penerapan $45,83 \%$. Sumber air berasal dari air tanah yang dialiri menggunakan pipa serta dalam kondisi yang baik. Air yang digunakan untuk proses pengolahan berupa air mengalir, air tidak keruh, tidak berbau, dan tidak berwarna. Namun, tidak dilakukan pemeriksaan untuk parameter standar kualitas air yang digunakan.

Limbah yang dihasilkan dari produksi rendang sebagian besar dalam bentuk limbah padat. Limbah padat yang dihasilkan berupa batok kelapa yang berasal dari proses persiapan bahan, sedangkan limbah yang dihasilkan selama proses pengolahan adalah arang kayu bakar yang dikumpulkan di satu tempat dan dijual kembali. Limbah cair yang dihasilkan seperti air cucian bahan dan air cucian alatalat produksi dialirkan melalui saluran air menuju kolam ikan yang berada tidak jauh dari bangunan. Istana Rendang Jambak belum melakukan pengolahan terhadap asap yang dihasilkan selama proses pemasakan. Terdapat 1 toilet yang terpisah dari bangunan produksi dengan kondisi yang baik dan terawat, namun tidak dilengkapi dengan fasilitas sanitasi 
Tabel 1. Penerapan GMP di produsen Istana Rendang Jambak

\begin{tabular}{llllll}
\hline No Parameter & \multicolumn{5}{c}{ Penilaian } \\
\cline { 2 - 5 } & 0 & 1 & 2 & 3 & 4 \\
\hline
\end{tabular}

1 Lokasi dan Lingkungan

Lokasi

1. Jalan dalam dan luar pabrik dalam kondisi baik

$\mathrm{X}$

2. Saluran pembuangan air disekitar pabrik berfungsi baik

3. Tidak terdapat genangan air $\mathrm{X}$ maupun banjir

4. Bebas tumpukan sampah $\quad \mathrm{X}$

5. Bebas rumput liar dan $\quad \mathrm{X}$ semak-semak

\section{Lingkungan}

6. Bebas dari area daerah

kotor, daerah kering dan

berdebu, daerah berpenduduk

padat, persawahan, daerah pem-

buangan sampah, dan daerah penumpukan barang bekas

7. Bebas dari polusi perpro- $\mathrm{X} \quad \mathrm{X}$ dusenan luar yang dapat

mencemari

\begin{tabular}{|c|c|c|c|c|c|c|}
\hline \multicolumn{3}{|c|}{ Total $(9 / 28) \times 100 \%=25.00 \%$} & \multirow[b]{2}{*}{1} & \multirow[b]{2}{*}{2} & \multirow[b]{2}{*}{3} & \multirow[b]{2}{*}{4} \\
\hline 2 & Bangunan & 0 & & & & \\
\hline & $\begin{array}{l}\text { Desain dan Tata Letak } \\
\text { Bangunan }\end{array}$ & & & & & \\
\hline & $\begin{array}{l}\text { 1. Ruang pokok sesuai dengan } \\
\text { kondisi peralatan, kapasitas } \\
\text { produksi dan jumlah karyawan. }\end{array}$ & & & $\mathrm{X}$ & & \\
\hline & $\begin{array}{l}\text { 2. Tata letak ruangan sesuai } \\
\text { urutan proses produksi }\end{array}$ & $\mathrm{X}$ & & & & \\
\hline & $\begin{array}{l}\text { 3. Ruang pelengkap sesuai } \\
\text { dengan jumlah karyawan }\end{array}$ & & & & $\mathrm{X}$ & \\
\hline & $\begin{array}{l}\text { 4. Ruang pelengkap sesuai urutan } \\
\text { kegiatan }\end{array}$ & & & & & $\mathrm{X}$ \\
\hline & Lantai & & & & & \\
\hline & 5. Rapat atau kedap air & & & & & $\mathrm{X}$ \\
\hline & $\begin{array}{l}\text { 6. Tahan terhadap air, basa, } \\
\text { garam, dan bahan kimia lainnya }\end{array}$ & & & & & $\mathrm{X}$ \\
\hline & $\begin{array}{l}\text { 7. Halus, tidak licin dan mudah } \\
\text { dibersihkan }\end{array}$ & & & & & $\mathrm{X}$ \\
\hline & 8. Keramik tidak retak atau pecah & & & & & $\mathrm{X}$ \\
\hline & $\begin{array}{l}\text { 9.Pertemuan antara lantai dan } \\
\text { dinding tidak membentuk sudut } \\
\text { siku-siku namun melengkung } \\
\text { serta rapat air }\end{array}$ & & & & & $\mathrm{X}$ \\
\hline & Dinding & & & & & \\
\hline & 10. Tidak terkelupas & $\mathrm{X}$ & & & & \\
\hline & $\begin{array}{l}\text { 11. Bersih dari debu dan kotoran } \\
\text { lain }\end{array}$ & & & $X$ & & \\
\hline & $\begin{array}{l}\text { 12. Dinding berlapis keramik } \\
\text { yang rapat/ kedap air minimal } 2 \\
\text { m dari permukaan lantai }\end{array}$ & & & & & $\mathrm{X}$ \\
\hline
\end{tabular}

\begin{tabular}{lllllll}
\hline No & Parameter & \multicolumn{4}{c}{ Penilaian } \\
\cline { 2 - 6 } & & 0 & 1 & 2 & 3 & 4 \\
\hline $\begin{array}{l}\text { 13. Pertemuan antara dinding } \\
\text { dengan dinding tidak boleh } \\
\text { membentuk siku-siku namun } \\
\text { melengkung serta rapat air }\end{array}$ & & & & & & \\
& & & & & \\
\end{tabular}

Atap

14. Tahan lama, tahan air, tidak $X$ bocor, dan tidak mudah pecah

Langit-langit

15. Tidak terkelupas, tidak

berlubang dan tidak retak

16. Tahan lama dan mudah

dibersihkan

17. Permukaan halus dan

berwarna terang

\section{Pintu}

18. Dari bahan yang tahan lama, $\mathrm{X}$ kuat, dan tidak mudah pecah

19. Pintu tidak rusak dan ditutup $\quad X$ dengan baik

20. Membuka keluar

\section{Jendela}

21. Tidak pecah

X

22. Dapat ditutup dengan baik

\section{Penerangan}

23. Lampu tidak pecah

$\mathrm{X}$

24. Lampu berpenutup

X

25. Berfungsi dengan baik

26. Cukup terang dan tidak remang-remang

Ventilasi dan pengaturan suhu

27. Mampu menjamin peredaran udara dengan baik

28. Mampu menghilangkan gas, uap, asap, debu, dan panas

29. Dalam keadaan bersih engkapi dengan alat yang dapat mencegah masuknya kotoran kedalam rangan serta mudah dibersihkan

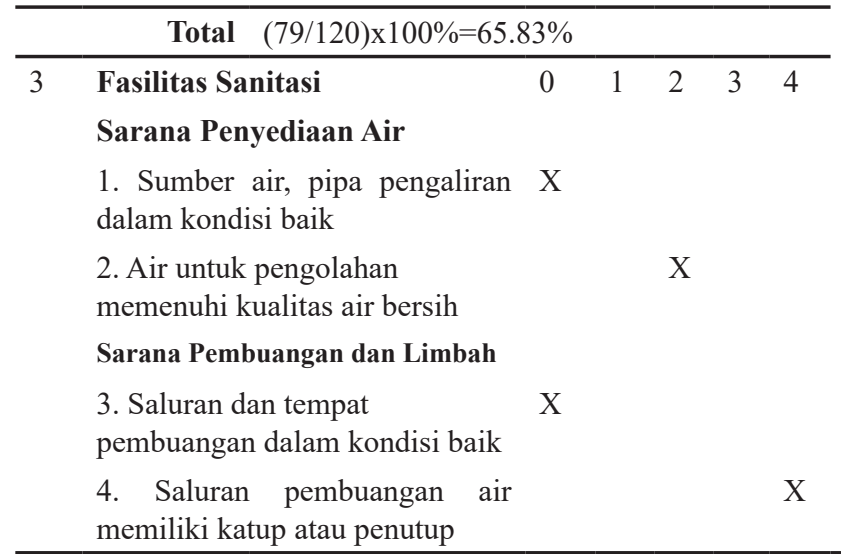




\begin{tabular}{|c|c|c|c|c|c|c|c|c|c|c|c|c|c|}
\hline \multirow[t]{2}{*}{ No } & \multirow[t]{2}{*}{ Parameter } & \multicolumn{5}{|c|}{ Penilaian } & \multirow[t]{2}{*}{ No } & \multirow[t]{2}{*}{ Parameter } & \multicolumn{5}{|c|}{ Penilaian } \\
\hline & & 0 & 1 & 2 & 3 & 4 & & & 0 & 1 & 2 & 3 & 4 \\
\hline & $\begin{array}{l}\text { 5. Sarana pembuangan harus } \\
\text { dapat mengolah dan membuang }\end{array}$ & & & $\mathrm{X}$ & & & & $\begin{array}{l}\text { 3. Jadwal pembersihan dilakukan } \\
\text { dengan baik }\end{array}$ & & & $\mathrm{X}$ & & \\
\hline & limbah padat, cair, dan gas yang & & & & & & & Tata Letak Mesin/Peralatan & & & & & \\
\hline & $\begin{array}{l}\text { dapat menimbulkan pencemaran } \\
\text { lingkungan }\end{array}$ & & & & & & & 4. Diletakkan ditempat yang & $\mathrm{X}$ & & & & \\
\hline & Toilet & & & & & & & 5 Memudahkan nerawatan & & $\mathrm{X}$ & & & \\
\hline & 6. Ruangan dalam keadaan bersih & & $\mathrm{X}$ & & & & & pembersihan dan pencucian & & & & & \\
\hline & 7. Tidak terdapat hama & $\mathrm{X}$ & & & & & & 6. Berfungsi sesuai dengan tujuan & & $\mathrm{X}$ & & & \\
\hline & 8. Memiliki cahaya yang cukup & & & $\mathrm{X}$ & & & & kegunaan dalam proses produksi & & & & & \\
\hline & $\begin{array}{l}\text { 9. Memiliki tempat sampah ber- } \\
\text { penutup dengan pijakan sebagai }\end{array}$ & & & & & $\mathrm{X}$ & & $\begin{array}{l}\text { Pengawasan dan Pemantauan } \\
\text { Mesin/Peralatan }\end{array}$ & & & & & \\
\hline & pembukanya & & & & & & & 7. Selalu dalam diawasi, & $\mathrm{X}$ & & & & \\
\hline & 10. Lantai tidak tergenang air & $\mathrm{X}$ & & & & & & diperiksa dan dipantau & & & & & \\
\hline & $\begin{array}{l}\text { 11. Tersedia alas kaki khusus } \\
\text { toilet }\end{array}$ & & & & & $\mathrm{X}$ & & $\begin{array}{l}\text { 8. Dilengkapi dengan alat } \\
\text { pengatur dan pengendali kelem- }\end{array}$ & & & & & $\mathrm{X}$ \\
\hline & $\begin{array}{l}\text { 12. Tersedia fasilitas cuci tangan } \\
\text { (wastafel, air sabun pengering }\end{array}$ & & & & $\mathrm{X}$ & & & $\begin{array}{l}\text { baban, aliran udara dan perleng- } \\
\text { kapan lainnya }\end{array}$ & & & & & \\
\hline & tangan, dan cairan sanitasi) & & & & & & & $(11 / 32) \times 100 \%=34.38^{\circ}$ & & & & & \\
\hline & 13. Tersedia peringatan cuci tan- & & & & & $\mathrm{X}$ & 5 & Bahan & 0 & 1 & 2 & 3 & 4 \\
\hline & gan setelah menggunakan toilet & & & & & & & Bahan Baku, Bahan & & & & & \\
\hline & 14. Pintu toilet selalu tertutup & & & & & $\mathrm{X}$ & & Tambahan, Penolong, dan BTP & & & & & \\
\hline & $\begin{array}{l}\text { 15. Letak tidak terbuka langsung } \\
\text { dengan ruangan pengolahan }\end{array}$ & $\mathrm{X}$ & & & & & & $\begin{array}{l}\text { 1. Dituangkan dalam bentuk for- } \\
\text { mula dasar }\end{array}$ & & $\mathrm{X}$ & & & \\
\hline & $\begin{array}{l}\text { 16. Jumlahnya mencukupi den- } \\
\text { gan karyawan yang bekerja (1-10 }\end{array}$ & $\mathrm{X}$ & & & & & & $\begin{array}{l}\text { 2. Tidak rusak, busuk, atau men- } \\
\text { gandung bahan-bahan berbahaya }\end{array}$ & $\mathrm{X}$ & & & & \\
\hline & orang $=1$ toilet/kamar mandi) & & & & & & & 3. Tidak merugikan/membaha- & $\mathrm{X}$ & & & & \\
\hline & Sarana Cuci Tangan & & & & & & & yakan kesehatan dan memenuhi & & & & & \\
\hline & 17. Jumlahnya mencukupi den- & & & & & $\mathrm{X}$ & & persyaratan mutu & & & & & \\
\hline & gan jumlah karyawan & & & & & & & Air & & & & & \\
\hline & $\begin{array}{l}\text { 18. Terdapat sabun cair dan alat } \\
\text { pengering serta cairan sanitasi }\end{array}$ & & & & $\mathrm{X}$ & & & $\begin{array}{l}\text { 4. Air memenuhi persyaratan air } \\
\text { minum/air bersih }\end{array}$ & & & $\mathrm{X}$ & & \\
\hline & $\begin{array}{l}\text { 19. Sumber air mengalir dengan } \\
\text { lancar }\end{array}$ & $\mathrm{X}$ & & & & & & $\begin{array}{l}\text { 5. Air yang kontak langsung den- } \\
\text { gan bahan pangan olahan harus }\end{array}$ & $\mathrm{X}$ & & & & \\
\hline & 20. Saluran tidak tersumbat & $\mathrm{X}$ & & & & & & memenuhi persyaratan air bersih. & & & & & \\
\hline & Sarana Higiene Karyawan & & & & & & & $(3 / 20) \times 100 \%=15.00 \%$ & & & & & \\
\hline & 21. Terdapat sarana pencuci tan- & & & & $\mathrm{X}$ & & 6 & Proses Pengolahan & 0 & 1 & 2 & 3 & 4 \\
\hline & $\begin{array}{l}\text { gan yang lengkap dengan sabun } \\
\text { cair dan alat pengering }\end{array}$ & & & & & & & $\begin{array}{l}\text { 1. Untuk jenis produk harus ada } \\
\text { formula dasar yang menyebutkan }\end{array}$ & $\mathrm{X}$ & & & & \\
\hline & 22. Fasilitas ganti pakaian dengan & & & & & $\mathrm{X}$ & & bahan baku dan jumlah bahan & & & & & \\
\hline & jumlah karyawan disesuaikan & & & & & & & 2. Setiap produk harus memiliki & $\mathrm{X}$ & & & & \\
\hline & $\begin{array}{l}\text { 23. Tempat penyimpanan pa- } \\
\text { kaian dan luar kerja terpisah }\end{array}$ & & & & & $\mathrm{X}$ & & $\begin{array}{l}\text { tahap tahap proses pengolahan } \\
\text { termasuk hal hal penting terkait }\end{array}$ & & & & & \\
\hline & 24. Tempat penyimpanan sepatu & & & & & $\mathrm{X}$ & & & & & & & \\
\hline & kerja dan sepatu luar terpisah & & & & & & & 3. Faktor-faktor yang mempen- & & & & $\mathrm{X}$ & \\
\hline & Total $(52 / 96) \times 100 \%=54.17$ & & & & & & & golahan seperti waktu, suhu, & & & & & \\
\hline 4 & Peralatan Produksi & 0 & 1 & 2 & 3 & 4 & & tekanan dan sebagainya harus & & & & & \\
\hline & 1. Permukaan yang kontak den- & & & $\mathrm{X}$ & & & & tercatat dan memiliki pedoman & & & & & \\
\hline & $\begin{array}{l}\text { gan makanan halus, tidak ber- } \\
\text { lubang, tidak mengelupas, tidak } \\
\text { menyerap air, dan tidak berkarat }\end{array}$ & & & & & & & $\begin{array}{l}\text { 4. Bahan yang digunakan me- } \\
\text { menuhi standar mutu yang } \\
\text { digunakan }\end{array}$ & & $\mathrm{X}$ & & & \\
\hline & 2. Tidak mengkontaminasi & & $\mathrm{X}$ & & & & & $(4 / 20) \times 100 \%=20.00 \%$ & & & & & \\
\hline
\end{tabular}


Indriani et al.

Jurnal Ilmu Produksi dan Teknologi Hasil Peternakan 9 (3): 127-137

\begin{tabular}{|c|c|c|c|c|c|c|}
\hline \multirow[t]{2}{*}{ No } & \multirow[t]{2}{*}{ Parameter } & \multicolumn{5}{|c|}{ Penilaian } \\
\hline & & 0 & 1 & 2 & 3 & 4 \\
\hline \multirow[t]{4}{*}{7} & Produk Akhir & 0 & 1 & 2 & 3 & 4 \\
\hline & $\begin{array}{l}\text { 1. Produk akhir memenuhi } \\
\text { standar mutu }\end{array}$ & & & $\mathrm{X}$ & & \\
\hline & $\begin{array}{l}\text { 2. Produk akhir aman } \\
\text { dikonsumsi (berdasarkan hasil } \\
\text { pengujian organoleptik, fisika, } \\
\text { kimia, dan mikrobiologi) }\end{array}$ & & & $\mathrm{X}$ & & \\
\hline & $(4 / 8) \times 100 \%=50.00 \%$ & & & & & \\
\hline \multirow[t]{4}{*}{8} & Laboratorium & & & & & \\
\hline & $\begin{array}{l}\text { 1. Memiliki laboratorium } \\
\text { pemeriksaan terhadap bahan } \\
\text { baku,bahan tambahan, bahan } \\
\text { penolong,dan produk akhir }\end{array}$ & & & & & $\mathrm{X}$ \\
\hline & $\begin{array}{l}\text { 2. Pemeriksaan menyebutkan } \\
\text { nama makanan, tanggal } \\
\text { pembuatan, tanggal } \\
\text { pengambilan, jumlah contoh, } \\
\text { kode produksi, jenis } \\
\text { pemeriksaan, kesimpulan } \\
\text { pemeriksaan, nama pemeriksa }\end{array}$ & & & & & $\mathrm{X}$ \\
\hline & $(8 / 8) \times 100 \%=100 \%$ & & & & & \\
\hline \multirow[t]{7}{*}{9} & Karyawan & 0 & 1 & 2 & 3 & 4 \\
\hline & $\begin{array}{l}\text { 1. Selalu menjaga kebersihan } \\
\text { badan }\end{array}$ & & $\mathrm{X}$ & & & \\
\hline & $\begin{array}{l}\text { 2. Menggunakan pakaian kerja } \\
\text { yang lengkap (penutup kepala, } \\
\text { sarung tangan, sepatu, dll) }\end{array}$ & & & & $\mathrm{X}$ & \\
\hline & $\begin{array}{l}\text { 3. Karyawan selalu mencuci } \\
\text { tangan dengan sabun saat } \\
\text { sebelum memulai melakukan } \\
\text { pengolahan }\end{array}$ & & $\mathrm{X}$ & & & \\
\hline & $\begin{array}{l}\text { 4. Karyawan selalu mencuci } \\
\text { tangan dengan sabun saat } \\
\text { sesudah melakukan pengolahan }\end{array}$ & & & & & $\mathrm{X}$ \\
\hline & $\begin{array}{l}\text { 5. Karyawan tidak makan, } \\
\text { merokok, meludah atau } \\
\text { melakukan tindakan yang } \\
\text { mencemari produk }\end{array}$ & & & $\mathrm{X}$ & & \\
\hline & $(10 / 20) \times 100 \%=55.00$ & & & & & \\
\hline \multirow[t]{7}{*}{10} & Wadah dan Pembungkus & 0 & 1 & 2 & 3 & \\
\hline & $\begin{array}{l}\text { 1. Tidak menimbulkan racun dan } \\
\text { tidak menimbulkan } \\
\text { penyimpangan yang berbahaya }\end{array}$ & $\mathrm{X}$ & & & & \\
\hline & $\begin{array}{l}\text { 2. Menjamin keutuhan dan } \\
\text { keaslian produk }\end{array}$ & $\mathrm{X}$ & & & & \\
\hline & $\begin{array}{l}\text { 3. Melindungi dan } \\
\text { mempertahankan mutu produk }\end{array}$ & $\mathrm{X}$ & & & & \\
\hline & $\begin{array}{l}\text { 4. Tidak berpengaruh dan } \\
\text { bereaksi dengan makanan yang } \\
\text { dikemas }\end{array}$ & $\mathrm{X}$ & & & & \\
\hline & $\begin{array}{l}\text { 5. Tahan perlakuan selama } \\
\text { pengolahan, pengangkutan, dan } \\
\text { peredaran }\end{array}$ & $\mathrm{X}$ & & & & \\
\hline & $(0 / 20) \times 100 \%=0.00 \%$ & & & & & \\
\hline
\end{tabular}

\begin{tabular}{|c|c|c|c|c|c|c|}
\hline \multirow[t]{2}{*}{ No } & \multirow[t]{2}{*}{ Parameter } & \multicolumn{5}{|c|}{ Penilaian } \\
\hline & & 0 & 1 & 2 & 3 & 4 \\
\hline \multirow[t]{3}{*}{11} & Label & & & & & \\
\hline & $\begin{array}{l}\text { 1. Label produk akhir minimal } \\
\text { sesuai dengan PP nomor } 69 \text { tahun } \\
1999 \text { tentang label dan iklan } \\
\text { pangan yaitu tercantum merk } \\
\text { dagang dan jenis rasa, setiap } \\
\text { jenis produk diberi warna yang } \\
\text { berbeda, komposisi sesuai } \\
\text { dengan isi, tanggal kadaluarsa, } \\
\text { nama produsen, serta logo } \\
\text { sertifikasi halal dari MUI }\end{array}$ & & & $\mathrm{X}$ & & \\
\hline & $(2 / 4) \times 100 \%=50.00 \%$ & & & & & \\
\hline \multirow[t]{7}{*}{12} & Penyimpanan & 0 & 1 & 2 & 3 & 4 \\
\hline & Area Penyimpanan Bahan Baku & & & & & \\
\hline & 1. Ruangan dalam keadaan bersih & & & $\mathrm{X}$ & & \\
\hline & 2. Ruangan dalam keadaan rapi & & $\mathrm{X}$ & & & \\
\hline & 3. Tidak terdapat hama & $\mathrm{X}$ & & & & \\
\hline & 4. Memiliki cahaya yang cukup & & & $\mathrm{X}$ & & \\
\hline & 5. Sirkulasi udara dalam ruang & & $\mathrm{X}$ & & & \\
\hline
\end{tabular}

baik, tidak panas, bau, berasap, yang dapat merugikan kesehatan

6. Penyimpanan sesuai dengan $\mathrm{X}$ label

7. Bahan baku disimpan dengan ketentuan sebagai berikut :

A) jarak bahan baku ke lantai minimal $15 \mathrm{~cm}$

B) jarak bahan baku ke dinding $5 \mathrm{~cm}$

$\mathrm{X}$

C) jarak bahan baku ke langit $\mathrm{X}$ langit $60 \mathrm{~cm}$

8. Stok bahan diatur dengan first $\mathrm{X}$ in first out(FIFO)

9. Terdapat data penyimpanan $\mathrm{X}$ bahan baku

Area penyimpanan produk akhir

10. Ruangan dalam keadaan $\mathrm{X}$ bersih

11. Ruangan dalam keadaan rapi

$\mathrm{X}$

12. Tidak terdapat hama $\quad \mathrm{X}$

13. Memiliki cahaya yang cukup

$\mathrm{X}$

14. Stok bahan diatur dengan $\mathrm{X}$ FIFO

15 terdapat data penyimpanan produk

Total $\quad(19 / 72) \times 100 \%=26.39 \%$

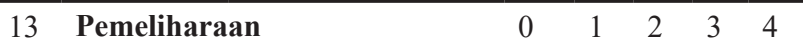

1. Bangunan dan bagiannya dipelihara dan dilakukan sanitasi secara berkala hingga selalu bersih dan berfungsi dengan baik 


\begin{tabular}{|c|c|c|c|c|c|c|}
\hline \multirow[t]{2}{*}{ No } & \multirow[t]{2}{*}{ Parameter } & \multicolumn{5}{|c|}{ Penilaian } \\
\hline & & 0 & 1 & 2 & 3 & 4 \\
\hline & $\begin{array}{l}\text { 2. Harus dilakukan pencegahan } \\
\text { masuknya serangga, binatang } \\
\text { pengerat, dan binatang lainnya } \\
\text { ke area produksi }\end{array}$ & & & $\mathrm{X}$ & & \\
\hline & $\begin{array}{l}\text { 3. Pembasmian jasad renik, } \\
\text { serangga dan binatang pengerat } \\
\text { dengan menggunakan } \\
\text { desinfektan, insektisida, atau } \\
\text { rodentisida harus dilakukan } \\
\text { hati-hati dan dibatasi }\end{array}$ & & & $\mathrm{X}$ & & \\
\hline & $\begin{array}{l}\text { 4. Buangan harus diolah agar } \\
\text { tidak mengganggu } \\
\text { kesehatan karyawan dan } \\
\text { mencemari lingkungan }\end{array}$ & & $\mathrm{X}$ & & & \\
\hline & $\begin{array}{l}\text { 5. Alat dan perlengkapan } \\
\text { dikenakan tindak sanitasi dan } \\
\text { diletakkan sesuai dengan } \\
\text { tempatnya }\end{array}$ & & & $\mathrm{X}$ & & \\
\hline & Total & $(11 / 2$ & TI & $0 \%=$ & 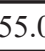 & \\
\hline & Total Penilaian & 213 & & & & \\
\hline
\end{tabular}

secara berkelanjutan. Fasilitas yang seharusnya disediakan terdiri dari sarana hygiene karyawan yang dilengkapi dengan pengering tangan dan sabun cair, tersedianya ruang ganti karyawan, ruang loker penyimpanan pakaian dan sepatu lab dengan pakaian dan sepatu luar, dan sarana pembilasan sepatu (Rudiyanto 2016).

\section{Peralatan Produksi}

Mesin atau peralatan produksi yang digunakan selama proses pengolahan harus memenuhi standar yaitu dalam hal teknik, bersifat tidak toksik, mutu dan hygiene, tahan karat, mudah dipelihara, kuat, tidak menyerap air, tidak mengelupas, dibersihkan, dan disanitasi (Rudiyanto 2016). Mesin/peralatan yang digunakan saat proses produksi memiliki nilai $63.62 \%$ yang berarti cukup memenuhi. Alat produksi yang kontak langsung dengan bahan terbuat dari bahan yang baik dan berfungsi sebagaimana semestinya.

\section{Bahan}

Bahan baku serta bahan tambahan yang digunakan untuk memproduksi harus menggunakan bahan yang sesuai dengan standar mutu yang berlaku dan tidak membahayakan ataupun merugikan kesehatan konsumen (2016). Bahan yang digunakan selama proses produksi terdiri atas dua bahan, yaitu bahan mentah dan bahan pengemas. Bahan mentah yang digunakan terdiri dari daging, santan kelapa, cabe merah, bawang putih, bawang merah, daun salam, dan garam. Daging dibeli di rumah potong hewan, santan kelapa diperas secara manual di tempat produksi, dan bahan lainnya yang dibeli dipasar. Rendang daging di Istana Rendang Jambak tidak menggunakan bahan tambahan pangan (BTP).

\section{Proses Pengolahan}

Proses pengolahan di Istana Rendang Jambak telah dilaksanakan sesuai prosedur yang ada namun belum dijalankan secara benar. Proses pengolahan memiliki nilai $80.00 \%$ yang berarti memenuhi persyaratan GMP. Proses pengolahan rendang di Istana Rendang Jambak menjaga kualitas produk dengan baik dan sangat memperhatikan kebersihan produk mulai dari persiapan hingga penyimpanan. Namun, proses pengolahan produk belum terstandar secara spesifik dikarenakan tidak ada pedoman produksi rendang yang tercatat mengenai faktor yang dapat mempengaruhi produk akhir. Dibutuhkan standar pedoman kualitas yang akan menjadi acuan dalam proses pembuatan rendang.

\section{Produk Akhir}

Produk akhir yang dihasilkan berupa rendang daging yang dikemas dengan plastik dengan ukuran 200 g hingga $5 \mathrm{~kg}$. Rendang yang telah matang didiamkan ditempat pengolahan hingga rendang dalam keadaan dingin lalu disimpan diwadah tertutup. Kegiatan tersebut memungkinkan terjadinya pencemaran produk akibat didiamkan ditempat terbuka yang dilewati pekerja. Kekurangan lainnya yang terjadi pada proses ini tidak dilakukan pengujian kimia dan mikrobiologi.

\section{Laboratorium}

Laboratorium merupakan tempat dilakukannya eksperimen, riset ilmiah, pengukuran ataupun pelatihan ilmiah. Keberadaan laboratorium dalam produsen memudahkan pengujian bahan baku, bahan tambahan, bahan penolong dan BTP yang masuk kedalam tempat produksi serta mutu produk yang dihasilkan (Winarno 2011). Laboratorium Istana Rendang Jambak memperoleh nilai $0.00 \%$ yang berarti tidak memenuhi persyaratan GMP. Produsen rendang Istana Rendang Jambak merupakan produsen pangan yang masih berskala kecil sehingga belum mempunyai laboratorium untuk pemeriksaan bahan baku maupun produk akhir, seharusnya produsen yang bergerak dalam bidang produksi pangan diharuskan memiliki laboratorium untuk melakukan uji fisik, kimia, dan mikrobiologis terhadap bahan dan produk sesuai Peraturan Menteri Kesehatan.

\section{Karyawan}

Karyawan menjadi salah satu aspek penilaian GMP yang terbagi ke dalam kesehatan karyawan dan kebersihan karyawan, karyawan memegang peranan penting dalam sanitasi makanan karena merupakan sumber potensial mikroba yang menyebabkan penyakit yang berpindah melalui makanan (Rauf 2013). Menurut Rudiyanto (2016) karyawan memiliki standar umum dalam bekerja dengan tidak menggunakan aksesoris yang dapat mencemarkan produk, tidak makan dan minum selama proses produksi, serta diharuskan memakai pakaian pelindung, menggunakan penutup kepala, sarung tangan, dan sepatu pelindung (khusus lab). Karyawan yang bekerja di rumah produksi rendang Istana Rendang Jambak sebanyak 10 orang, namun karena masa pandemik Covid-19 karyawan bekerja secara bergantian sebanyak 2-3 orang perhari. Karyawan di rumah produksi rendang Istana Rendang Jambak memiliki nilai $45.00 \%$ yang berarti kurang memenuhi persyaratan GMP. Karyawan yang bekerja tidak menggunakan sarung tangan dan sepatu pelindung, namun menggunakan penutup kepala dan berpakaian bersih. Kondisi tersebut dapat mencemari 
bahan-bahan serta produk rendang pada saat proses produksi.

\section{Wadah dan Pembungkusan}

Wadah dan pembungkusan harus dapat melindungi dan mempertahankan mutu isi terhadap pengaruh luar, menjamin keutuhan dan keasliannya, serta tidak merugikan/ membahayakan konsumen (Winarno 2011). Wadah yang digunakan produsen rendang Istana Rendang Jambak terbuat dari dua jenis plastik, yaitu jenis polyethylene $(\mathrm{PE})$ dan jenis polypropylene (PP). Penggunaan dua lampis kemasan plastik untuk memastikan tidak ada kebocoran dan mencegah pengaruh luar yang dapat merusak mutu rendang.

\section{Label}

Label memiliki nilai $50.00 \%$ yang berarti kurang memenuhi persyaratan GMP karena label yang digunakan belum memenuhi UU Nomor 69 tahun 1999 tentang label dan iklan pangan yang mengharuskan mencantumkan nama produk, daftar bahan yang digunakan, volume, nama produsen, tanggal produksi dan kadaluarsa, serta kategori suhu penyimpanan. Label produk Istana Rendang Jambak tidak mencantumkan tanggal produksi, tanggal kadaluarsa, dan persyaratan suhu penyimpanan.

\section{Penyimpanan}

Penyimpanan terbagi ke dalam dua jenis yaitu penyimpanan bahan mentah dan penyimpanan produk akhir (Rudiyanto 2016). Penyimpan Istana Rendang Jambak memiliki nilai $73.61 \%$ aspek tersebut dikategorikan memenuhi. Bahan baku dan produk akhir disimpan secara terpisah, bahan baku disimpan diruang penyimpanan bahan mentah seperti kelapa. Namun untuk bahan yang mudah rusak seperti daging dibeli secukupnya agar langsung diolah dan bisa mencegah pencemaran ataupun pembusukan pada daging. Istana Rendang Jambak membuat rendang daging sesuai pesanan, rendang yang telah jadi dan didiamkan langsung dikemas dan dikirimkan kepada pemesan sehingga tidak terjadi penyimpanan rendang daging dalam waktu lama.

\section{Pemeliharaan}

Pemeliharaan bangunan dan bagian-bagian ruangan di produsen rendang Istana Rendang Jambak memperoleh nilai $45.00 \%$ yang dikategorikan kurang memenuhi persyaratan GMP. Selama pengamatan pembersihan dan tindakan sanitasi hanya dilakukan untuk lantai yang terlihat kotor, atap bangunan tidak dibersihkan sehingga berwarna gelap, terdapat sarang laba-laba disudut ruangan, serta tidak dilakukan perawatan terhadap lantai tempat produksi yang sudah rusak dan pecah-pecah.

\section{Penerapan Sanitation Standard Operating Procedures (SSOP)}

Penerapan SSOP sangat diperlukan agar mendukung terlaksananya GMP dengan baik. Penyimpangan yang terjadi selama pelaksanaan SSOP akan menyebabkan kondisi lingkungan yang dapat menghasilkan kontaminasi silang terhadap produk. Dalam produsen pangan, sanitasi memegang peranan penting yang meliputi kegiatan secara aseptik dalam persiapan, pengolahan dan pengemasan produk makanan, pembersihan dan sanitasi pabrik serta lingkungan pabrik dan kesehatan pekerja (Rianti et al. 2018). Penerapan SSOP di lapangan beserta kondisi seharusnya pada produsen Istana Rendang Jambak dapat dilihat pada Tabel 2.

Tabel 2. Penerapan SSOP di podusen Istana Rendang Jambak

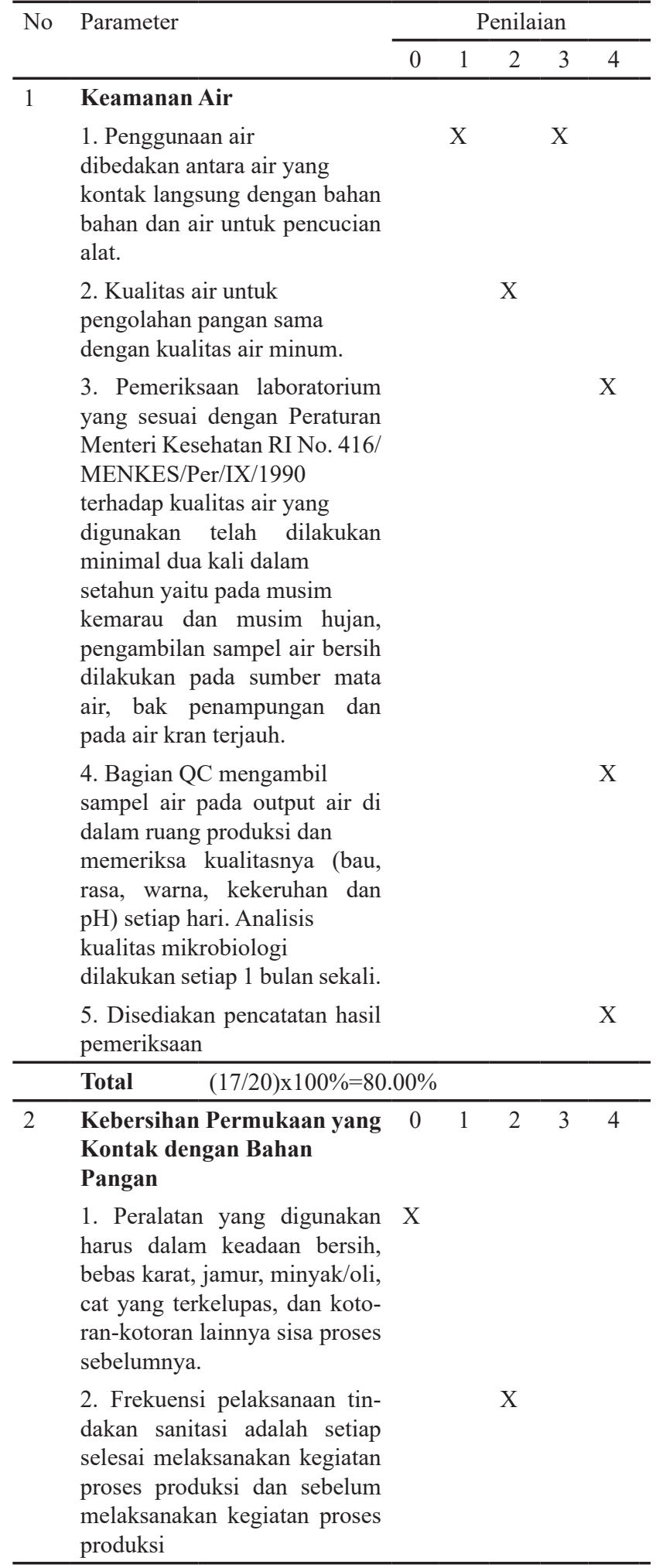




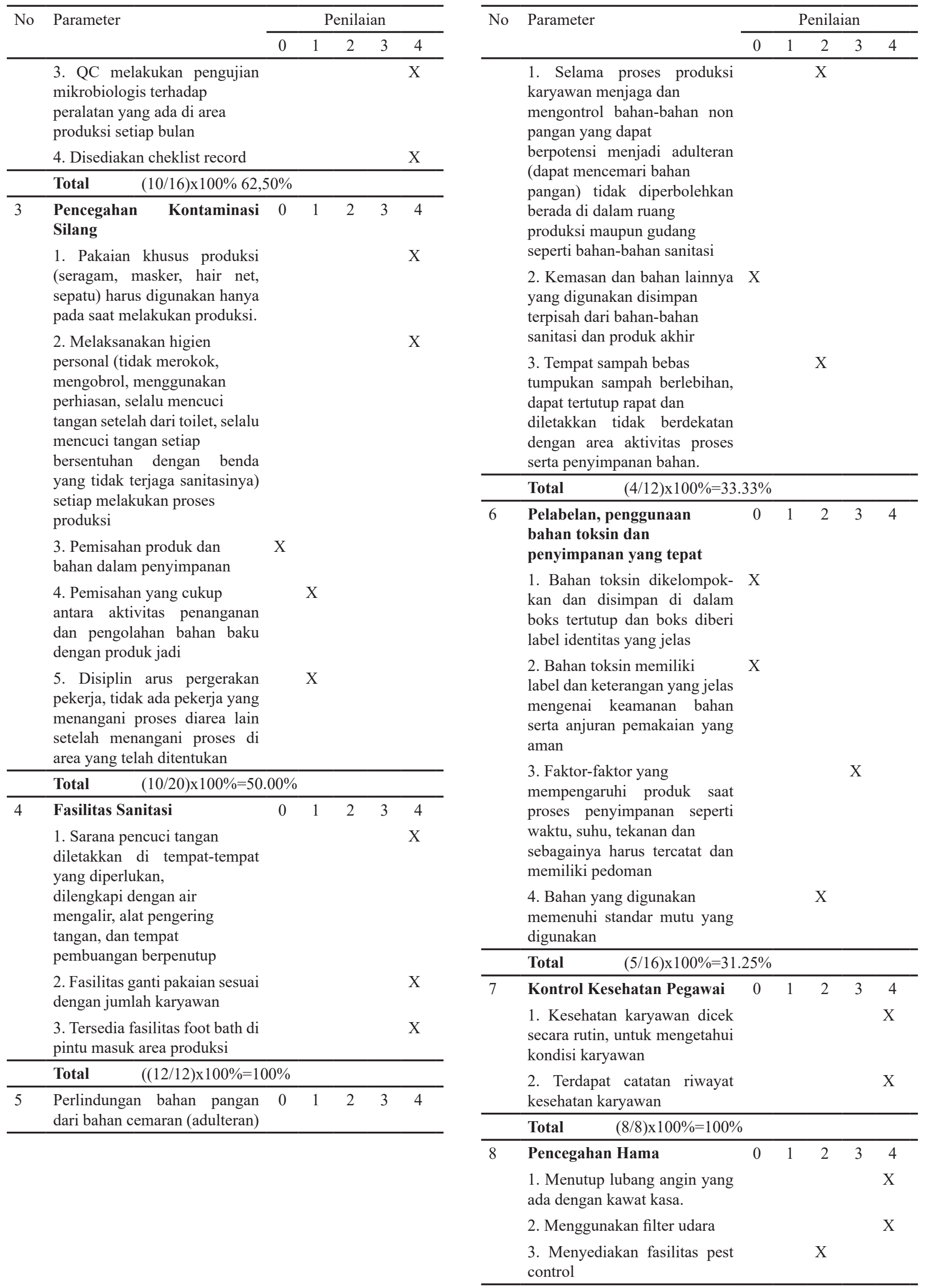




\begin{tabular}{lllllll}
\hline No & Parameter & \multicolumn{4}{c}{ Penilaian } \\
\cline { 2 - 6 } & 0 & 1 & 2 & 3 & 4 \\
\hline $\begin{array}{l}\text { 4. Dilakukan pembersihan } \\
\text { ruang produksi secara berkala }\end{array}$ & & & $\mathrm{X}$ \\
\hline Total $\quad(13 / 16) \times 100 \%=81.25 \%$ \\
\hline
\end{tabular}

\section{Keamanan Air}

Nilai penerapan SSOP produsen rendang Istana Rendang Jambak untuk aspek keamanan air memiliki nilai $15.00 \%$ yang berarti tidak memenuhi. Penggunaan air untuk keperluan di produsen Istana Rendang Jambak berasal dari tanah yang ditarik menggunakan mesin dan ditampung dalam tangki penampungan air. Air yang digunakan antara air yang kontak dengan bahan dan air yang digunakan untuk pencucian alat berasal dari air yang sama. Kualitas air yang digunakan mendekati kualitas air minum dalam aspek warna air dan bau air, air yang digunakan selama proses produksi juga digunakan sebagai air minum karyawan. Namun air yang digunakan tidak pernah dilakukan pengujian oleh Dinas Kesehatan, selain itu tidak dilakukan pemeriksaan rutin terhadap air yang digunakan.

\section{Kebersihan Permukaan yang Kontak dengan Bahan Pangan}

Kebersihan permukaan yang kontak dengan bahan pangan di produsen rendang Istana Rendang Jambak memiliki nilai $37.50 \%$ yang berarti sangat kurang memenuhi SSOP. Peralatan yang digunakan dalam kondisi bersih dan baik, setiap terjadi kerusakan alat akan langsung diganti dengan yang baru. Tindakan sanitasi pada kegiatas proses produksi hanya dilaksanakan setelah proses produksi dan tidak dilakukan lagi sebelum proses produksi. Tidak pernah dilakukan pengujian mikrobiologis terhadap peralatan dam tidak tersedia pencatatan hasil pemeriksaan.

\section{Pencegahan Kontaminasi Silang}

Tempat pengolahan makanan sangat diperhatikan untuk menghindari kontaminasi silang, hal yang sangat diperhatikan adalah tempat pengolahan, keadaan karyawan, pemisahan antara pakaian luar dan pakaian khusus tempat produksi. Penerapan pencegahan kontaminasi silang di produsen rendang Istana Rendang Jambak memiliki nilai $50.00 \%$ yang berarti kurang memenuhi SSOP. Pakaian khusus produksi tidak tersedia sehingga karyawan menggunakan pakaian dari luar seperti baju dan sandal, hal ini dapat mencemari produk karena mudah terpapar debu jalanan maupun kotoran-kotoran kecil yang menempel pada pakaian. Karyawan hanya menggunakan celemek dan penutup kepala yang disediakan, karyawan tidak menggunakan perhiasan, dan tidak merokok, namun masih mengobrol, makan dan minum ditempat produksi.

\section{Fasilitas Sanitasi}

Penerapan fasilitas sanitasi pada produsen rendan Istana Rendang Jambak memiliki nilai $0.00 \%$ yang berarti tidak memenuhi SSOP. Tidak disediakan sarana cuci tangan ditempat yang diperlukan, hanya tersedia sabun dengan air yang tidak mengalir. Tidak tersedia fasilitas ganti pakaian, serta fasilitas foot bath. Sebaiknya disediakan tempat untuk mencuci tangan lengkap dengan sabun, air mengalir dan pengering tangan untuk mempermudah pekerja dalam menjaga kebersihan tangan setelah memegang benda tertentu yang tidak berhubungan dengan alat produksi.

\section{Perlindungan Bahan Pangan dari Bahan Cemaran (Adulteran)}

Perlindungan dari bahan-bahan yang diduga sebagai sumber cemaran memiliki nilai $66.67 \%$ atau cukup memenuhi SSOP. Selama proses produksi tidak terdapat bahan non pangan yang berpotensi menjadi adulterant. Bahan-bahan pangan dan bahan sanitasi disimpan terpisah. Tempat sampah bebas dari tumpukan dan terletak tidak berdekatan dengan area proses produksi, namun tempat sampah tidak memiliki tutup.

\section{Pelabelan, Penggunaan Bahan Toksin, dan Penyimpanan yang Tepat}

Pelabelan pada produsen pengolahan pangan sangatlah penting agar dilakukan penanganan dan penyimpanan yang sesuai untuk memberi jaminan keamanan kesehatan konsumen (Anggraini dan Yudhastuti 2014). Penerapan pada aspek ini cukup memenuhi SSOP (nilai 68.75\%). Tidak terdapat bahan toksin disekitar ruang produksi. Bahan toksin tersimpan di ruang terpisah yang cukup jauh dari ruang produksi dan diberi label. Bahan yang digunakan memenuhi standar mutu secara fisik, namun tidak dilakukan uji secara kimia dan mikrobiologi. Faktor yang mempengaruhi penyimpanan produk tidak tercatat dan tidak memiliki pedoman.

\section{Kontrol Kesehatan Karyawan}

Kontrol kesehatan karyawan penting untuk dilaksanakan karena kesehatan karyawan dapat menjadi salah satu sumber kontaminasi, namun meski kesehatan karyawan sangat penting untuk menjaga kontaminasi silang, produsen rendang Istana Rendang Jambak tidak melakukan pemeriksaan rutin ataupun riwayat kesehatan karyawan. Nilai pada aspek ini adalah $0.00 \%$ atau tidak memenuhi SSOP, karena terkadang pegawai tetap bekerja jika sakitnya tidak parah seperti batuk dan demam.

\section{Pencegahan Hama}

Pencegahan hama yang dilakukan produsen rendang Istana Rendang Jambak hanya memasang kawat diatas dinding untuk mencegah hewan besar masuk, seperti tikus. Lubang angin tidak ditutup dengan kawat kasa dan tidak menggunakan filter udara. Pembersihan ruangan dilakukan setiap setelah produksi namun tanpa menggunakan desinfektan. Meski ruangan produksi semi tertutup, tidak terdapat lalat atau hama lainnya di tempat produksi. 


\section{KESIMPULAN}

Penilaian kesesuaian penerapan GMP di produsen rendang Istana Rendang Jambak memperoleh nilai $34.17 \%-85.00 \%$, dengan nilai penyimpangan 213 dari nilai keseluruhan 468 yang berarti penyimpangan dalam tingkat sedang sehingga penerapan GMP dikatakan kurang memenuhi ketetapan Menteri Kesehatan RI Nomor 23/ MENKES/SK/1987 tentang Cara Produksi Makanan yang Baik (CPMB). Penilaian kesesuaian penerapan SSOP memperoleh nilai antara $0.00 \%-68.75 \%$, dengan nilai penyimpangan 79 dari nilai keseluruhan 120 yang berarti penyimpangan berada dalam tingkat berat atau sangat kurang memenuhi ketentuan FDA mengenai SSOP. Tingginya angka penyimpangan penerapan GMP dan SSOP menandakan rendahnya tingkat pencegahan kontaminasi selama proses produksi.

\section{UCAPAN TERIMA KASIH}

Ucapan terima kasih kami sampaikan kepada Pemilik dan karyawan Istana Rendang Jambak atas dukungannya pada penelitian ini.

\section{DAFTAR PUSTAKA}

Anggraini. T., \& R. Yudhastuti. 2014. Penerapan Good Manifacturing Practices pada industry rumah tangga kerupuk teripang di sukolilo Surabaya. J. Kes Lingkungan. 7(2):148-158

Hanidah. I. I., A. T. Mulyono, R. Andoyo, E. Mardawati, \& S. Huda. 2018. Penerapan good manufacturing practices sebagai upaya peningkatan kualiatas produk olahan ikan di pesisir Eretan-Indramayu. J Agribisnis dan Sosial Ekonomi Pertanian. 3(1):359-426.

Kasnodihardjo, \& E. Elsi. 2013. Deskripsi sanitasi lingkungan, perilaku ibu dan kesehatan anak. J Kesehatan Masyarakat Nasional.7(9):415-420.

Lukman. D. W. 2001. Good Manifacturing Parctices (GMP). Pelatihan untuk Pelatih (Training of Trainers/ TQT). Penerapan Hazard Analysis Critical Control Point. Kerjasama Fakultas Kedokteran Hewan IPB dengan Dirjen Bina Produksi Peternakan. Departemen Pertanian Republik Indonesia, Bogor.

Putra, E. A. 2015. Anak berkesulitan belajar di sekolah dasar se-kelurahan Kalumbuk Padang. J Ilmiah Pendidikan Khusus. 4(3):71-76.

Rauf, R. 2013. Sanitasi Pangan \& HACCP. Graha Ilmu, Yogyakarta

Rianti, A., A. Christoper, D. Lestari, \& W. E. Kiyat. 2018. Penerapan keaman dan sanitasi pangan pada produksi minuman sehat kacang-kacangan UMKM Jukajo Sukses Mulia di Kabupaten Tangerang. J Agroteknologi. 12(2):167-175.

Rudiyanto, H. 2016. Kajian Good Manufacturing Practices dan kualitas mutu pada Wingko berdasarkan SNI-014311-1996. J. Kes. Lingkungan. 8(2):148-157.

Triharjono, A., B. D. Probowati, \& M. Fakhry. 2013. Evaluasi sanitation standard operating precedures kerupuk amplang di UD Sarina Kecamatan Kalianget Kabupaten Sumenep. J Agrointek. 7(2):76-83.

Wicaksani. A. L., \& R. Adriyani. 2017. Penerapan HACCP dalam proses produksi menu daging rendang di inflight catering. J Gizi Indonesia. 12(1):88-97.

Winarno. F. G. 2011. Good Manufacturing Practices (GMP) Cara Pengolahan Pangan yang Baik. M-BRIO PRESS, Bogor. 